\title{
15. ASPECTS OF MUSICAL LANGUAGE OF HEITOR VILLA-LOBOS' CONCERT STUDIES
}

Daniel Dragomirescu ${ }^{137}$

Abstract: Careful research has shown that the Brazilian composer's works are inaccurate in terms of indications yet respecting every parameter of music. Regarding the technical aspects, which represent the quintessence in the interpretation of string instruments, and in our case, a dark realm due to the lack of their representation on the score, the performer must make balanced decisions based on imagination and education acquired during years of study.

Key words: guitar, studies, style and guitar performance

\section{Study no. 1}

Study no. 1 ("Allegro non troppo"), in E minor, is a right-hand technique study based on a fixed arpeggio formula: $p$ i p i p mi a m a i mpipi. As it is about arpeggios, the right hand must be in a permanent sensation of relaxation, required for the accuracy of the technical and interpretative achievement. This composition resembles "Bachianas brasileiras", which is an ingenious miniature"138, "The Well-Tempered Clavier" making its presence felt all the time. Bach's influence is not felt in any detail, being obvious more at the structural level of Lobos' music, as is the case in this first study. The patterns of the arpeggios are written in the same spirit as those of Prelude in C major or Little Prelude.

$$
\text { E.g., } 1^{139}
$$

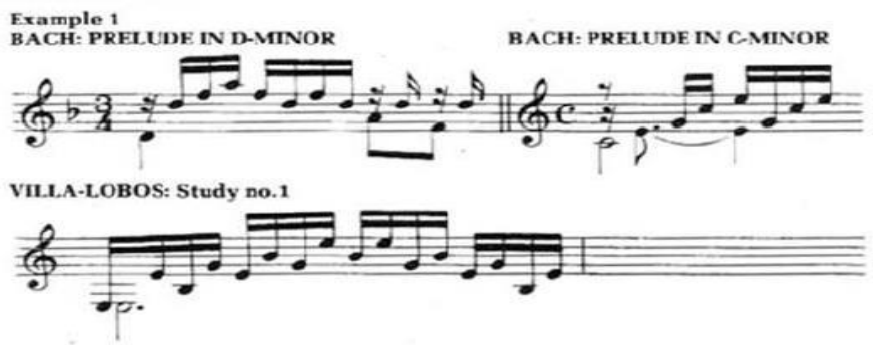

The use of free strings and chromatic harmonics on a single pattern allow the maximum use of the dynamic capacity of guitar, as there are various forms of practice, such as: with rhythmic formulas, staccato, in both pinching styles of tyrando and apoyando as well as by changing the toning order of the sounds of the arpeggio.

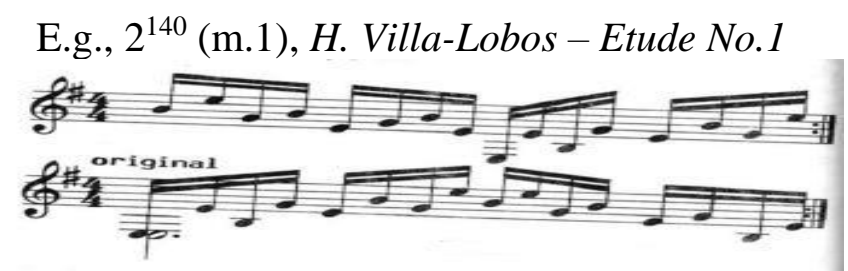

Eliot Fisk states that: "This imprecision is not necessarily undesirable

\footnotetext{
137 Associate Professor PhD., "George Enescu” National University of Arts from Iaşi, Romania, email: dany_guitar2000@yahoo.com

138 Turibio Santos, Santos, Turibio, 1985, Heitor Villa Lobos and the guitar, originally published by the Museu Villa-Lobos, 1975, first published in English by Wise Owl Music, Gurtnacloona, Bantry, Co.Cork, Ireland, p.22

${ }^{139}$ Carlos Bonell, Bonell, Carlos, ,,Guitar” (vol.11 din 9 aprilie, apărută în 1983), no.1, p.9

140 Turibio Santos, op.cit., p.22
} 
because it creates the interpreter a huge amount of creative space".

Study no. 1 was composed in Paris in 1929 and is intended for the development of guitarist technology. The guitar of that period had gut strings, not nylon strings, like today's ones. When the play was published, Andrés Segovia, the Spanish guitarist to whom the play was dedicated, nevertheless sang on plastic strings, which means that Villa-Lobos accepted such strings but did not show anything in the play about this fact. By avoiding the marking of Metronome, along with the name of the tempo "Allegro non troppo "(fast but not excessive), the composer allows the performer to determine the speed of the performance. Thus, the term is relative, depending somehow on the temperament of the individual, being approached differently by a 20 -year-old man and otherwise by an older man.

As it is a play intended for guitar, the continuous semiquavers organized in $4 / 4$ measure at the time of the interpretation do not comply with the values indicated by the partition. The accuracy of their scoring calls for a huge number of relations, combinations, breaks, voices, Lobos considering that the extra-support is self-evident, by the words "pour guitare ". The decision of each interpreter to let the notes sound derives from the information that they are independent of the sheet music.

A similar blur also occurs when highlighting the dynamic parameters. The compliance with the "piano" marking of measure 1 offers two options for interpretation: 1 . that each note is played at the same level of intensity; 2. that there are sonority variations between the sounds of the chord. One possible solution for achieving the phrasing is to encourage a long crescendo during the first 11 measures, as the bass goes up to the master chord $B$ major7. Within this crescendo, subtle graduations of dynamics can be improvised on different portions. The key indication which is very important for interpretation is even the left-hand phrasing ( $p$ i $p$ i p m i a ma $i m p i p i$ ), this combination inevitably producing a continuous shine resulting from the slight variations in the tone quality differences between the thumb and the other fingers. But the sheet music does not indicate exactly what is to be highlighted, with every instrumentalist highlighting his musical knowledge, his thinking, and his imagination.

The difficult exchanges of chords performed with the left hand can be resolved in the first phase by a very rare study, also helping to strengthen the righthand pattern. One method that can be a solution for the successful completion thereof is that of "cold" exchange, without the right hand pinching the strings. Thus, the configurations of the chords change, making it compulsory to simultaneously place on the strings all the fingers used for each position. I recommend a simple exercise in which these chords must be studied until they connect easily from the beginning to end. Therefore, the legato $(s)(\mathrm{m} .24 .25)$ and the harmonics (m.32.33) are replaced by E minor from the first measure, helping these exchanges take place smoothly, without interruption.

$$
\text { E.g., } 3
$$

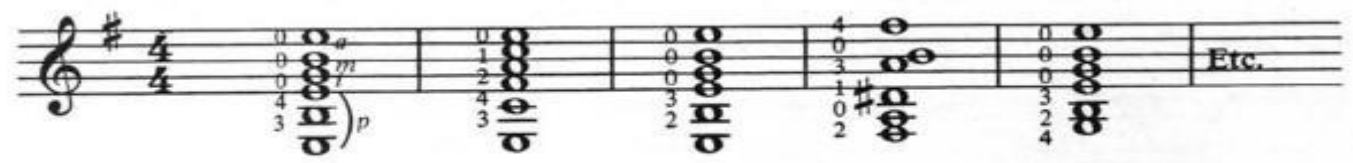

The most common problem encountered when approaching this play is the 
speed of the right hand. But as I said before, apart from the speed, the study contains the repetition of the arpeggio pattern of the right hand, with the left hand moving from chord to chord. This repetition can be effectively studied in the following way. First, the sequence is played very slowly so that any mistake is eliminated. Then, it is repeated, by doubling the speed, and after it returns to a rare tempo for the next sequence (respectively, the next chord). Rarely studied and thought, with the constant participation of the attention, the first sequence helps establishing the sound accuracy by the precision of the attack style and provides a favourable start to repeat it at double speed, acting as a control on the tendency to hurry. The modality shown is beneficial because the speed can only be doubled for one sequence, the left hand changing the chords and complying with the same tempo, to achieve relaxation during the performance of the work.

A possible exercise to effectively solve the arpeggio of the right hand is to divide it into two parts. In E.g., 4 A, the phrasing of beats 2 and 3 (on the first four strings) shall constitute in a pattern to be studied until the perfect coordination of the fingers is obtained. E.g., $4 \mathrm{~B}$ indicates the way of practicing the pattern on all six strings of the guitar, including the chords from the previous example. The first and fourth beats of that measure represent the problem of the movement of the right hand up and down on all the strings, with the aim of clarity. A good exercise to increase the speed of pinching with the fingers is E.g., $4 \mathrm{C}$, which can be studied on all the chords of the entire excerpt from E.g., 3. Two types of phrasing may be applied, since some guitarists prefer $p m p i$ on the first beat, in exchange for the original one indicated in the partition: $p i p i$.

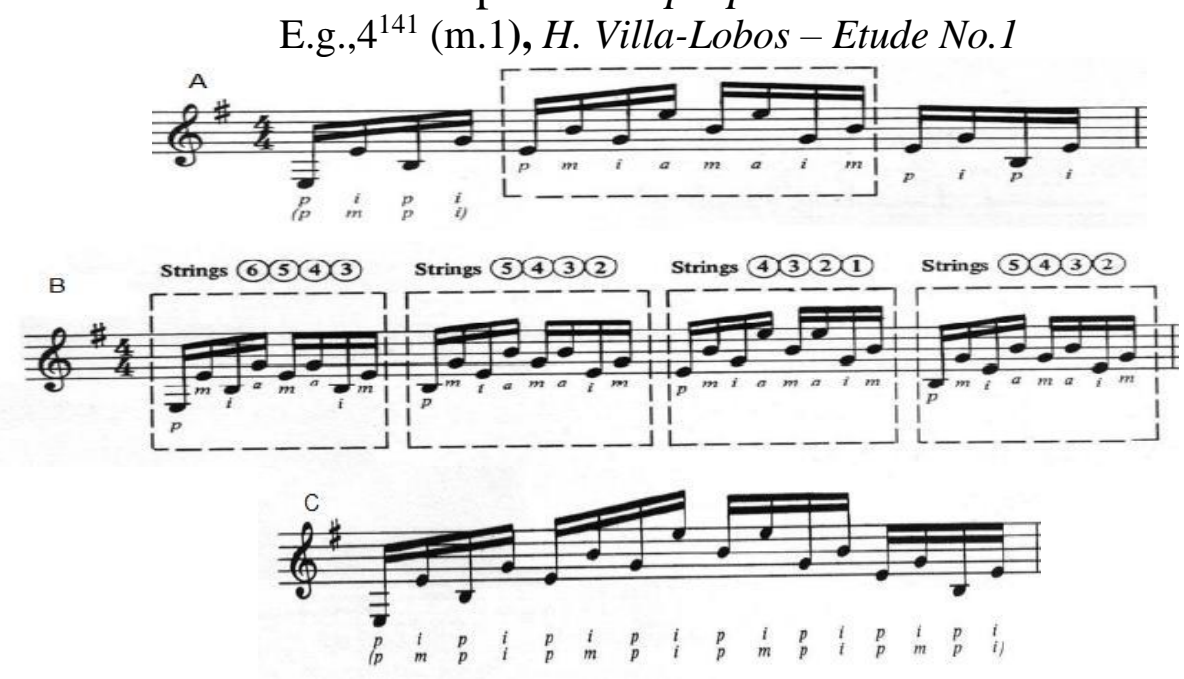

Coming back to obtaining a considerable speed, it is recommended that a sustained study is conducted at low speed, or even very rarely if a mistake is made. Then, the tempo is gradually increased until the one desired and required is achieved. This method helps to remove any errors that tend to become automatic. So, if there are still uncertainties while practising at high speed, then it is necessary to return to the strenuous work of the study at low speed. The most difficult part is the passage with legato in beats 24-25.

The following example shows how they can be practiced in the pattern of the $\mathrm{E}$ minor chord, both ascending and descending. By lowering the first and third sixteenth of each beat of the measure until $B$ minor or $F \#$ minor, the entire length

${ }^{141}$ Charles Postlewate, Etude 1, from „Guitar Master Class” by Ronald Sherrod, 1980, p.2 
of the fingerboard will be covered, removing the possibility that the study of the fragment becomes tiresome and boring. The solution also contributes to the qualitative achievement of the legato process over the entire surface of the grief, and the practice of two other phrasings for the left hand (2-3 and 3-4) results in the use of the normal one (1-2) in a more comfortable way.

E.g., 5

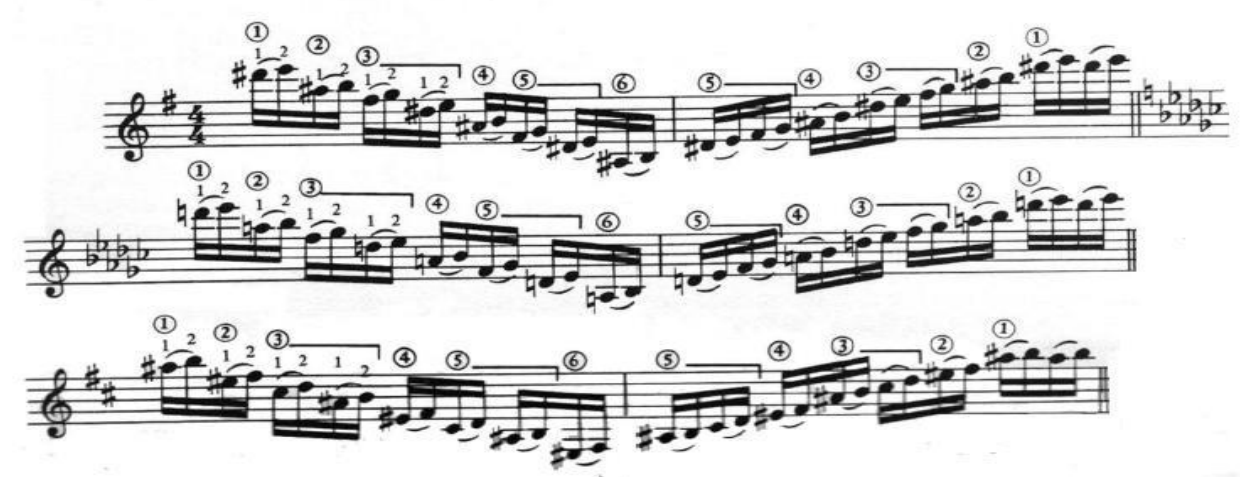

The following example represents a variation of phrasing which helps to consolidate the previous exercise, developing both legatos, ascending, and descending, by using all finger combinations: 1-2, 2-3, 3-4.

E.g., 6

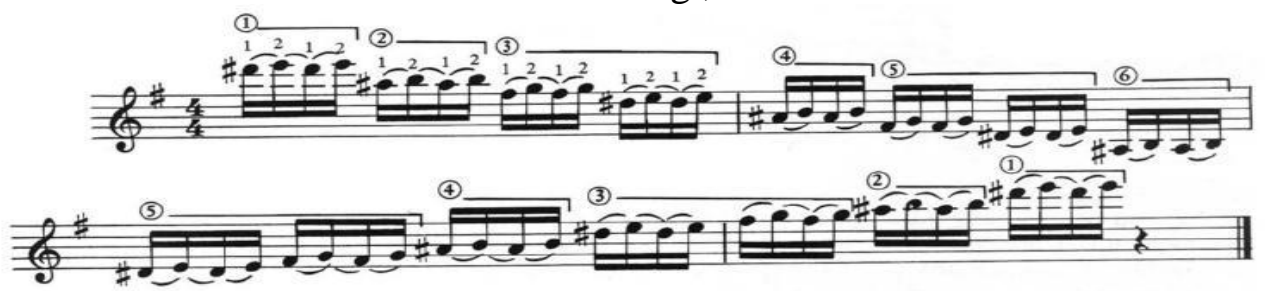

The emission of harmonics in measures 32 and 33 involves a short blow to the strings with the fingers of the left-hand during pinching, first following the original pattern of the arpeggio and changing after that. To produce these crystal sounds without hesitations, I propose the rare study, with an attack in the register close to the snares.

As regards the timbre, the composer does not give us any indication of the use of the registers, sul ponticello" or, sul tasto", this remaining at the discretion of the interpreter. One possibility could be to move gradually from one register to the other to obtain a long crescendo, up to the chord B Major7 of the measure 11. For an adequate colour of the sounds, both types of vibrato can be used, of the finger or arm, highlighting both the emotional intensity (calm, quiet or threatening) and the printing of a pleasant character, especially for the last chord in the play. For the successful completion of Study No. 1, daily exercises have a decisive role in a broad design that helps to:

1. keep the hands in shape to sing anything required.

2. prepare mentally and physically for the concert repertoire.

They can be practiced using the metronome set to a rare tempo. The tempo is increased gradually, with attention focused on the uniformity of the tone, rhythm, and hues between the fingers of the right hand. The speed of the metronome can be increased when you feel comfortable with the old one. Increasing and decreasing this speed of exercise, the instrumentalist will have the chance to relax, becoming much more coordinated at low speeds. Most guitarists 
perform this Study in the fourth quarter $=144-176$. But it is recommended that practice should start half of these values or even less frequently.

Charles Postlewate confesses in a specialist article: "I am trying to extract as far as possible my daily exercises from new plays being studied, or from the old ones, familiar plays that must be preserved in good playing conditions. We must always remember that every exercise is worked to help with something on the actual or future repertoire and not just to start the daily study". ${ }^{142}$

\section{Study no. 2}

With the risk of repeating myself, I once again state that Study no. 2 is one of arpeggios, but not in the classic sense of the concept. In the age of the Baroque, this concept meant that the consecutive notes of a diatonic scale were fixed on different strings, using the arpeggio technique (campanellas). Here the traditional idea is not followed, so the phrasings of both hands raise most problems for the person who approaches the work.

As a first starting point, it should be noted that the meaning of the legato is very difficult to understand and has no logical development. So, while the first legato with which the study starts is performed naturally following the traditional spirit, in other places it is difficult to achieve (m.8, 9, 15 and 17) or even impossible (m.18, 19, 20, 23 and 25). The method in an ascending sense between the first two sixteenths of beat 1 of measure 8 ( $B$ with the first finger, key II and $E$ with the fourth finger, key VII, both on the 5th string) followed by $G$ and $B$ sung on free strings implies a sharp extension of the two fingers of the left hand, causing a discomfort during the interpretation, altering the feeling of relaxation needed to perform an arpeggio study. The intensity of this phenomenon varies according to the physical qualities of each instrumentalist's hand.

A large hand with long fingers will handle this phrasing very easily, while a small hand with short fingers will make a considerable effort, reaching as far as to feel muscle cramps. In conclusion, the first version of phrasing presented earlier can be embraced by instrumentalists whose physical qualities do not make them feel uncomfortable in successfully solving the passage. The second one, intended for those guitarists with shorter fingers, consists in making a legato of expression between the first two sixteenths, $B$ and $E$ so the first sixteenth is placed with the finger 2 on the string $A$ and the second with the finger 3 on the string $D$, practically following the pattern of the $E$ minor chord:

\section{E.g.,7 (m.8), H. Villa-Lobos - Etude No.2}

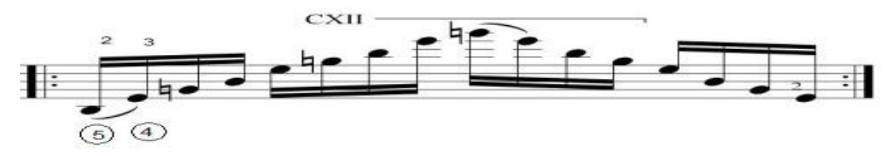

A similar thing also happens in measure 9, according to which after pressing on $B$ with the first finger on the fifth string, sound $D \#$ is attacked by ascending legato on the same string with the fourth finger, followed by F\#with the second finger on the fourth string and $A$ with the first finger on the third string. Again, there is a need for an extension between the extreme fingers of the left hand (1-4) but this time, not as demanding, being accessible to a hand whose fingers are

${ }^{142}$ Charles Postlewate, op.cit., p.1 
medium or smaller in length.

The compliance with the technical legato between $G$ and $C$ within measure 15 , involves the use of a phrasing difficult to achieve by the left hand and also having the same extension between the first and fourth fingers (e.g. below). Next to this version, I will offer another more comfortable one, which uses the full barre (on all six strings) placed in the position IV, but which turns the ascending legato into an expression one.

\section{E.g.8 (m.15), H. Villa-Lobos - Etude No.2}

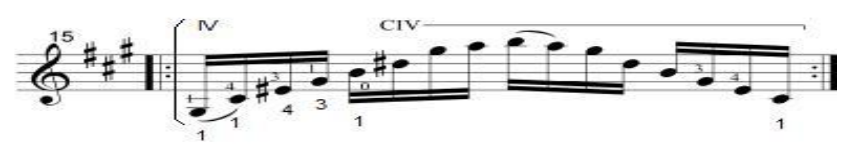

The same happens in measure 17, where the sounds $G \#$ with the first finger on the sixth string and $C \#$ with the fourth finger on the same string are played by the same type of legato (ascending). To resolve this sequence, I propose two models that can be followed by the fingers of the left hand, namely:

E.g.9 (m.17), H. Villa-Lobos - Etude No.2

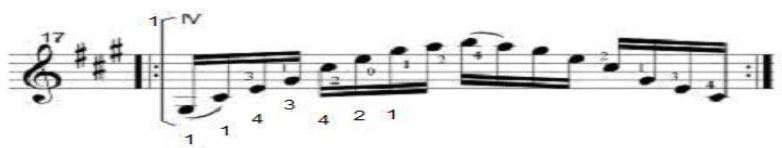

The phrasing indicated at the bottom of the portable is carried out by laying the full barre in space IV, the other fingers following the pattern of the C\# minor chord, turning the legato process marked on the first two sixteenths of beat 1 into one with expressive valences. For the following measures (No 18, 19, 20, 23, 25), although there are the same notations (legato), they cannot be technically complied with, so the only way is to choose a comfortable phrasing that gives the uniformity of colour and intensity to the respective arpeggios. In terms of indoor virtuosity cadence $(\mathrm{m} .10,11,12)$ which also involve special technical qualities, I suggest a variation of phrasing for both the right and the left hand, contributing to maintain the equality of rhythm and sound, doubled by a complete crescendo on the highest $A$ sound at, located on the XVII key.

E.g. 10 (m.9-12), H. Villa-Lobos - Etude No.2

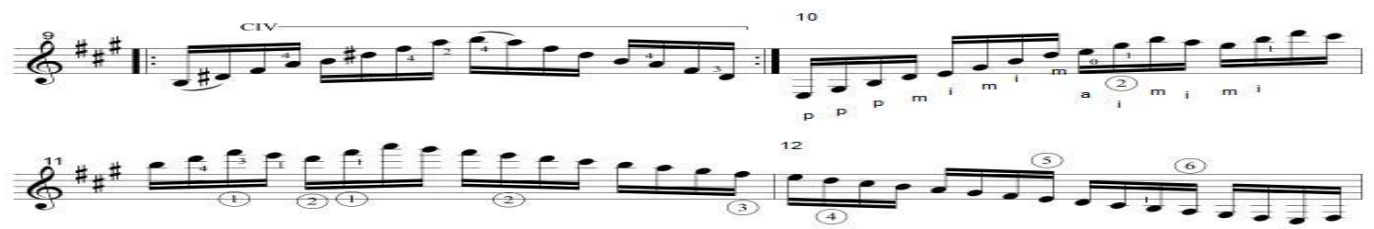

Often, many interpreters considered that in measure no.12, the last sixteenth on beat 4 should have been $G \#$ instead of $F \#$. But it may have been the wish of the composer, testified by the older records of the study. The sound material at the end of the work has raised many controversies among practitioners and not only. The interpretation of the harmonics on beat 4 of measure no. 26 and on beat 1 of measure 27 is very difficult to achieve although in the sheet music we have enough information shown to provide an appropriate version, information which, to the surprise of all, helps too little: 1. m.d. / m.g., 2. pizz., 3. harm. duples. 4. rall.

E.g. 11 (m.25-27), H. Villa-Lobos - Etude No.2

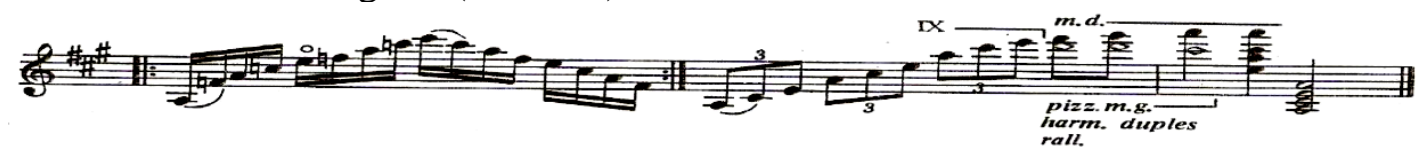


The discrepancy existing in the notation of the last two measures is that there are three marks calling for the harmonic approach of the two dyads of measure no. 26 and the first dyad of the following measure (no. 27). So, the sign "m.d." appears above the normal eights. Even if the sounds are not indicated as flageolets, there is a clear intention to be sung in the upper octave (as artificial harmonics), but they can also be played normally. The bottom line, with notes in the form of rhombus, contains the marking "m.g." making more precise reference to the natural flageolets, and for a clearer specification "harm. duplex" is added to the footer of the portable. The problem deepens with the occurrence of the indication"pizz.". Many practitioners do not respect this meaning by considering that it cannot be related to double harmonics, so they use different solutions to sing this passage. Some guitarists such as Barrueco, Santos or Yepes completely ignore these suggestions in the sheet music, when interpreting the fragment. In this context, the work ends with an ascending arpeggio on A major, culminating in a traditional cadence which serves as a calm response to the storm illustrated by the successions of arpeggios.

In his book" Heitor Villa-Lobos and the Guitar", Turibio Santos notes that" At the end of the play, the simultaneous use of harmonics and normal notes involves a particular technical difficulty" ${ }^{\prime 43}$. The blind acceptance of Abel Carlevaro's statement on the above-mentioned cadence of Study no.2 as this could be sung bitonally, seems a hasty one. Regarding this aspect, Ophee Matanya in his article entitled" How does it end?" says that if we extended the bitonal idea to technical refinements, however valuable these may be and to attribute such progress to Villa-Lobos, it would mean to create a memorial based on insufficient historical data, just as if we were linking the invention of dodecaphonic music to J. S. Bach.

In one of his works, Kevin Tolly shows that this end of the play has nothing to do with double flageolets and more, with bitonalism. His explanation is that the positioning of the" pizz" indication above the" m.g." creates a link between them, requiring that the left hand pinches into pizzicato. According to this idea, the passage can be performed on a single string, where" m.d." is intended to indicate the attack itself with the right hand and "pizz. - m.g." suggests a pinch on the same string by partially pressing with the fingers of the left hand. This method finds its application only on very good tools, with a perfect straight Griff, where the sounds in pizzicato sound clear. Moreover, "harm. duplex" marking, as Tolly says, would be a misprint.

Ricardo Iznaola offers the variant of the intonation of these harmonics by partially pressing on the strings with the fingers of the left hand resulting in some sounds, which though weak in intensity, can have a surprising effect. Since they are used for the first time in the guitarist literature, he has generically called them "partial sounds of Villa-Lobos" in memory of the great composer. Even if the author intended to complete this study by using a special technique for interpreting a mere cadence, such as the one known in contemporary music as a bitonal one, there is no evidence that it was intended to separate into two separate actions in which natural notes produced by pressing the strings with the fingers of the left 
hand must be played simultaneously with the harmonics made with the right hand.

Relating to the polytonalism of the Brazilian composer, Michael Jaffe concludes he is not present only in the plays intended for the guitar, considering that at the end of any composition, Lobos always clearly establishes the preponderance of a single central tone, approaching both tonal and polytonal in a traditional manner. As for the tempo in interpreting this end of study, many guitarists play it freely, I would even dare say at half the normal speed, precisely to facilitate the achievement of these double flageolets. Considering the disregarding of the instructions on the sheet music, the end can be dealt with in the original tempo (MM.116-164).

To balance the sound and rhythmic sides of the arpeggios, it is recommended to emphasize the sounds at the extremities. This is made possible by using a pinch method that combines both styles: tyrando for the notes inside the arpeggio sequence and apoyando for the beginning and the peak of the arpeggio.

E.g. 12 (m.1), H. Villa-Lobos -Etude No.2

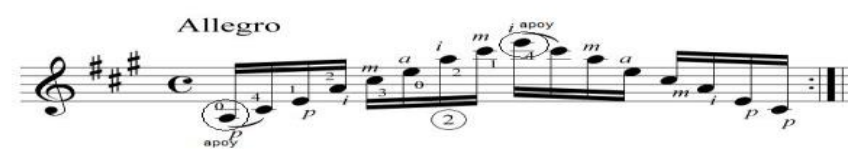

An additional technical problem is represented both by the accuracy of making legatos (ascending and descending) and by following an expressive consistency, regardless of the difficulties that may occur along the way (playing in high positions, musical scores passages, etc.).

Looking at the dynamics, the methods used to carry out a proper interpretation reveal once again the passion of the Brazilian for J. S. Bach's music. Thus, using the echo technique where the repetition of measures is played in piano gives the study an additional difficulty, with the right hand having to move permanently between the "sul ponticello" register next to the snares and the "sul tasto" in the fingerboard area. Embracing the dynamics in terraces principle, a crescendo will be built up until measure 3 , where, with the tension created by the arpeggio of the chord reduced to the A\#, the climax of the first musical phrase is emphasized. The following measure (no. 4) will be interpreted in a smaller shade, thus preparing the beginning of the subsequent sentence which starts in the 5th measure.

The tonal contrasts in measures 5, 6 and 7, 8 must be highlighted by performing the colour exchanges, the arpeggios of minor chords being played in the "sul tasto" register. A crescendo can be applied to the sequence passage (m.10, 11,12 ), finishing on the highest sound in the sequence ( $A$ on key XVII), followed by a decrescendo to announce the next verse, which is based on a succession of arpeggios, whose expressivity is influenced by the character of each chord in part.

The phrasing of the right hand is not always constant, which requires the interpreter to accumulate a large luggage of performing experience to maintain the smoothness and clarity when pinching the strings. This can be achieved by a rare and sustained study, the application of the phrasing being the same as the one at the time of the interpretation of the play at the appropriate speed. However, for the right hand it is possible to use a single arpeggio pattern repeatedly, but also several combinations of fingers, which at one time may be more difficult to comply with: 


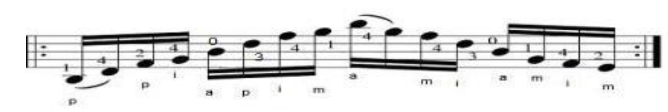

\section{Study no. 3}

Influenced by the teaching and creative work of the composers of previous times, Study no. 3 (together with the Studies 2, 9) is practically an exercise for the arpeggios in which legato notes and barres are integrated. But looking thoroughly, we will see that the attention is focused on the correct execution of the legato, as proof that the scalar passage in Study no. 1 reappears here too.

Study no. 3 is rather a beautiful play, with a higher degree of difficulty, with the notes themselves presenting some problems intended for the activity of the left hand. As I mentioned before, one of them is the indications of the legato between the sounds. For example, in measure 2, beat 1 , the first two notes are linked, this thing being achieved naturally. The same goes for the following measures: $\mathrm{m}$ 11/beat 1, m. 11/beat 4, m. 20/beat 1, m. 20/beat 2 .

There are also places where the legato is noted, but it could not be played. Instead, it is interpreted using the arpeggio technique for the right hand: $\mathrm{m}$. 8/beat 1 , the third and fourth sixteenth; m. 13/beat 2, the third and fourth sixteenth; $m$. 13/beat 3, third and fourth sixteenth.

Although few of these are cases where Villa-Lobos has indicated a preference for the toning of the loose strings, I believe that they should be respected. Such an example is present in measure no.17 (the last two notes on beat 3) where a legato involves such a string. In this context, every instrumentalist must decide which variant fits his interpreting concept. While Julian Bream, in this passage, opts for classic legato, other guitarists choose the free Strone. There are also a few aspects which create ambiguities in both the reading and interpretation of this work:

1) m.3/beat 1 Yepes plays $C$ in bass, while the other interpreters play $C \#$. Is it a read error or is it related to more thorough documentation?

2) m.11/beat 1 Yepes attacks the $G$ as the inner voice of the first chord, while others are pinching $G \#$. Could it be a mistake again?

3) m.14/beat 1 Here, it seems to be an inaccurate note of the duration of the first chord. This inaccuracy is a constant problem in Villa-Lobos' plays. If the time periods indicated were respected as closely as possible, we should choose one of the two options: we could give rise to an ambiguous phrasing, which is not specific to the guitar, or we could aspire to a solution closer to the instrument side by extending the accurate notation. The latter can be applied very well to measure 2 , beat 1 , stopping the inner voices of the chord and maintaining the sound of the bass.

4) m.15/beat 1 At the midvoice of the first chord, Julian Bream plays the $C$ note instead of $C \#$ (the version of a reading error is being speculated).

5) $\mathrm{m} .30 / \mathrm{beat} 1$ Each sound in the low or acute registry of the chord is indicated with a too long duration. A good solution for this chord would be to be considered as a quarter. 
6) m. 30/beat 2 (last measure) Here occurs a difficult problem from the harmonic point of view. Together with the first two indications $A 3$ and $D 4$ (which seem to mean nothing), another $D$ appears in the acute plane on the first string marked with a circle above. We are in the $D$ major tone, so we should look for some harmonics that match this tone. So the $A$ and $D$ notes are correct from this point of view, so we need to find out which numbers would suit them. I do not think that the figures present on the sheet music suggest the keys to be used, because by pinching the flageolet on the fourth string, the third key, we get an $A$ (which is in order) but the fourth key on the third string gives rise to a $B$ and, otherwise it is hard to believe that this play could end up with such a sound that is outside the original tone. There may be two possible explanations:

1) Instead of using the natural grading method by using the letters, the composer has chosen numbers here, accidentally, this being the wrong way to observe the sound material of the play's tone (the circles indicating the harmonics are also missing);

2) Another explanation would be that Villa-Lobos suggested a phrasing to create double harmonics. In this case, the $D$ above must not be played separately as a third flageolet.

None of the two options expressed above is very convincing, so most guitarists want to pinch two harmonics on the third and fourth strings in space VII. By playing this way, it is possible to sing the $D$ above at the same time as the other notes, but only a few interpreters do so. The end of this work gives rise to another ambiguous aspect. However, the 1928 manuscript clearly indicates that in measure 30 , the note in the plane below is not a flageolet, but a normal sound. Following Lobos' usual notary practice, the passage acquires a perfect meaning, so that $D$ on the $A$ chord is sung with the third finger, and the harmonic online $\mathrm{V}$ fourth string is sung with the fourth finger, being consistent with the height indicated above the portable: $\quad$ E.g., 14 (m.30), HH. Villa-Lobos - Etude No.3

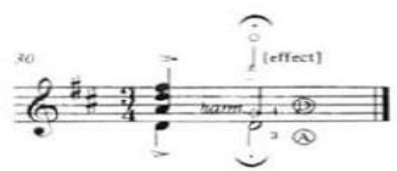

As far as the phrasings are concerned, although the manuscripts contain considerably more indications than the published sheets music, this does not mean that the latter should be completely rephrased. The musical and technical value derives from present notations. In Study no. 3, the movement of the left hand reveals both the concern for the legato, for the clarity of the ruling voice and for the effects specific to phrasing. One of the technical aspects is the tendency to link the spaced positions through rapid exchange along a single string, treating the relative force of the fingers with an impressive appearance.

E.g., 15 (m.9-10), H. Villa-Lobos - Etude No.3

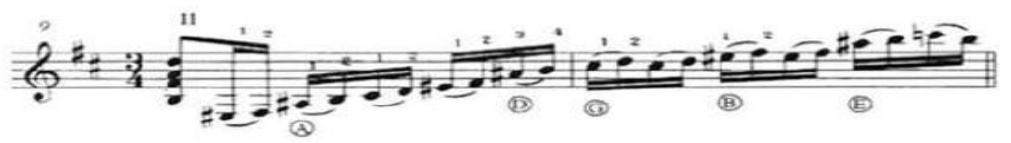

This play can be approached by also using variations in rhythm in order to practice the phrasings, the method contributing both to the increase of the tempo 
and to the clarity of the sounds sung through the legato process, the emphasis fell on each second note from the groups of two sixteenths.

E.g., $16^{144}$ (m.1), H. Villa-Lobos - Etude No.3

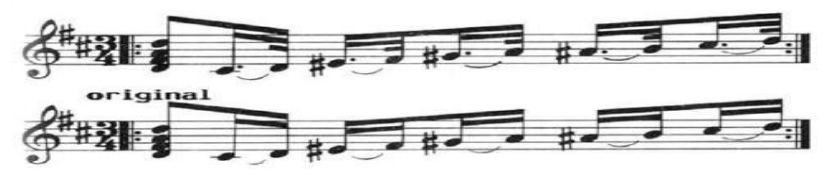

\section{Conclusions}

If any guitarist shall take into account these details and shall apply them, he/she shall certainly develop the level of interpretation of the entire repertoire. Since in the last decades the sound of the guitar has become a landmark of culture of Latino-American countries, we are motivated to concern ourselves with the promotion of a repertoire which shall include various musical works written by Latino-American composers born between the $19^{\text {th }}$ century and the middle of the $20^{\text {th }}$ century. In this age, important composers and interpreters of this geographical areas have distinguished themselves, and their contributions led to the extension of the technique and development of the language within the repertoire for classical guitar.

\section{References}

1. Arran, Johnn, Technical Hang-Ups,,Guitar” no.6, vol 12, January 1984, no.1

2. Bonell, Carlos, ,,Guitar” (vol.11 din 9 aprilie, apărută în 1983), no.1

3. Cubierta, Radames Giro, Gamboa, Rusky, 1982, Leo Brouwer, La Musica, Lo Cubano y la Innovacion, Editorial Letras Cubanas, Calle G. num.505, El Vedado, Ciudad de la Habana, Cuba, Sobre el autor

4. Danner, Peter, spring 1992, The Guitar in Latin-America. A personal view by Carlos Barbosa-Lima as told to Peter Danner, part 1, GFA Soundboard (XIX/1)

5. Dumond, Arnaud et Denis, Francoise Emmanuelle, 1988, Entretiens avec Leo Brouwer, Les Cahiers de La Guitare, trimestrul 4, Premiere rencontre, avec Arnaud Dumon

6. Duarte, John, The Preludes of Villa-Lobos. Some Notes, part 1, G.I. vol 13, no.1

7. Golea, Antoine, 1987, Muzica din noaptea timpurilor până în zorile noi, vol II, Editura Muzicală, Bucureşti

8. Goldspiel, Alan, 2000, A NEW LOOK AT MUSICAL STRUCTURE AND THE GUITAR IN THE MUSIC OF VILLA-LOBOS, GFA Soundboard, Fall

9. Ștefănescu, Ioana, 2002, O istorie a muzicii universale, Vol. IV, Editura Muzicală, București

10. Santos, Turibio, 1985, Heitor Villa Lobos and the guitar, originally published by the Museu Villa-Lobos, 1975, first published in English by Wise Owl Music, Gurtnacloona, Bantry, Co.Cork, Ireland

11. Tanenbaum, David, 1992, The essential Studies, study notes, insights and commentary on Leo Brouwer's 20 Estudios Sencillos, Guitar Solo Publications (GSP 28), San Francisco, 1992, Introduction

12. xxx 2006, Dicţionar de mari muzicieni, Editura Univers enciclopedic, Bucureşti

13. xxx 1990, Enciclopedia Marilor Maeştrii ai Muzicii, vol.V, Le Livre de Paris Hachette

14. en.wikipedia.org/wiki/Musician_Wren

${ }^{144}$ Turibio Santos, op.cit., p.23 